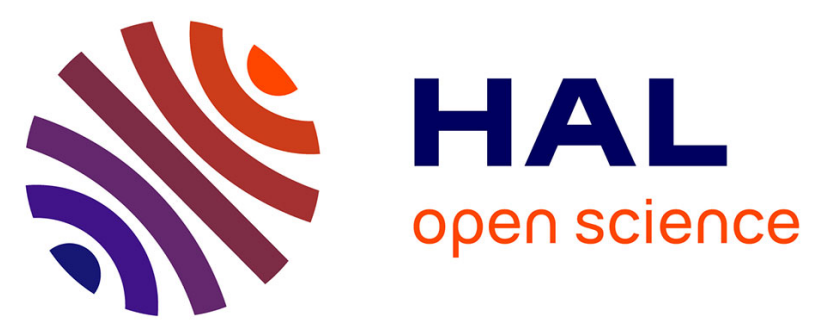

\title{
Absorption Spectroelectrochemistry on Mixed Perylenediimide-Based Self-Assembled Monolayers: Non-Linear Dependence of Absorbance versus Surface Coverage
}

Sihame Bkhach, Olivier Alévêque, Yohann Morille, Tony Breton, Piétrick Hudhomme, Christelle Gautier, Eric Levillain

\section{To cite this version:}

Sihame Bkhach, Olivier Alévêque, Yohann Morille, Tony Breton, Piétrick Hudhomme, et al.. Absorption Spectroelectrochemistry on Mixed Perylenediimide-Based Self-Assembled Monolayers: NonLinear Dependence of Absorbance versus Surface Coverage. ChemElectroChem, 2017, 4 (3), pp.601606. 10.1002/celc.201600770 . hal-02525068

\section{HAL Id: hal-02525068 \\ https://univ-angers.hal.science/hal-02525068}

Submitted on 30 Mar 2020

HAL is a multi-disciplinary open access archive for the deposit and dissemination of scientific research documents, whether they are published or not. The documents may come from teaching and research institutions in France or abroad, or from public or private research centers.
L'archive ouverte pluridisciplinaire HAL, est destinée au dépôt et à la diffusion de documents scientifiques de niveau recherche, publiés ou non, émanant des établissements d'enseignement et de recherche français ou étrangers, des laboratoires publics ou privés. 


\section{Absorption spectroelectrochemistry on mixed perylenediimide-based self-assembled monolayers: non-linear dependence of absorbance vs. surface coverage.}

Sihame Bkhach, Olivier Alévêque, Yohann Morille, Tony Breton, Piétrick Hudhomme, Christelle Gautier, Eric Levillain*

Université d'Angers, CNRS UMR 6200, MOLTECH-Anjou, 2 bd Lavoisier, 49045 ANGERS cedex, France.

* Corresponding authors: Tel.: (+33)241735090; Fax: (+33)241735405; E-mail: eric.levillain@univ-angers.fr

\begin{tabular}{l|l}
\hline ARTICLE INFO & ABSTRACT \\
\hline $\begin{array}{c}\text { Keywords: } \\
\text { Self-assembled monolayers } \\
\text { Spectroelectrochemistry }\end{array}$ & $\begin{array}{l}\text { The study of mixed self-assembled monolayers of perylenediimide and hexanethiol by cyclic } \\
\text { voltammetry and absorption spectroelectrochemistry leads to a non-linearity of absorbance } \\
\text { maxima as a function of the surface coverage. This unexpected result is supported by an } \\
\text { increasing of the average tilt angle at low coverage, suggesting that the dilution of redox } \\
\text { species via an alkanethiol would induce a change of the orientation of immobilized } \\
\text { chromophores and, therefore, a modification of the optical properties of the monolayer. }\end{array}$ \\
\hline
\end{tabular}

\section{Introduction}

Electrochemistry is known to be a powerful tool to probe redox-active self-assembled monolayers (SAMs) [1] and establish detailed structure-reactivity relationships for interfacial reactions, especially on mixed SAMs by taking advantage of its high sensitivity, specificity, accuracy and temporal resolution [2-6].

Concerning spectroelectrochemistry on (mixed) SAMs, a few works involving an electrochemical/spectroscopic coupling have been dedicated to this research field. They were essentially performed in potentiostatic conditions (i.e. fluorescence [7,8], PM-IRRAS [9], SERS [10], UV-visible absorption [11,12]). Even rarer still is the monitoring of a spectroscopic signature as a function of an electrical perturbation (potential step or linear scan) on SAMs. Only two recent works have been dedicated to absorption spectroelectrochemistry (A-SEC) coupled to cyclic voltammetry on redox SAMs. They have demonstrated the possibility of monitoring very low absorbance variations of electroactive species (thiophene [13] and perylenediimide) [14]) to extract voltabsorptograms of the corresponding SAMs. These works suggest that SAMs could be seen as highly concentrated solutions.

This communication focuses on the analysis of perylenediimide/alkanethiol mixed SAMs by A-SEC. The work seeks to extend the technical boundaries of A-SEC on SAMs (reproducibility, signal-to-noise ratio, instrument detection limit...) in order to establish structure-property relationships via the study of optical properties (i.e. absorbance) vs. surface coverage.

\section{Experimental}

\subsection{Chemicals, Au substrate and SAM preparation}

The synthesis of the dialkyl disulfide perylenediimide (PDI) 1 (Figure 1) was previously described [14]. We should take into account that the introduction of four chlorine atoms at the $1,6,7,12$ positions of the bay 
region enforces a considerable twisting close to $35-37^{\circ}$ of the PDI skeleton as a result of electrostatic repulsion and steric effects among the substituents [15-17].

Au substrates were prepared as previously described in [18] and were made immediately before use.

SAMs of 1 were prepared on fresh Au substrates $\left(0.2 \mathrm{~cm}^{2}\right)$ by immersion for $15 \mathrm{~min}$ in $0.5 \mathrm{mM}$ solution of 1 (i.e. $1 \mathrm{mM}$ per PDI moieties) in dichloromethane at $303 \mathrm{~K}$. Mixed SAMs were prepared using a successive adsorption protocol, by immersing SAMs of $\mathbf{1}$ in a millimolar hexanethiol solution for the appropriate time to achieve the expected surface coverage (i.e. from $1 \mathrm{~min}$ to $12 \mathrm{~h}$ ).

\subsection{Spectroelectrochemical experiments}

Electrochemical measurements were carried out with a Biologic SP-150 potentiostat driven by the EC-Lab software including ohmics drop compensation. Experiments were recorded in dry HPLC-grade dichloromethane with tetrabutylammonium hexafluorophosphate $\left(\mathrm{nBu}_{4} \mathrm{NPF}_{6}\right.$, electrochemical grade, Fluka) as supporting electrolyte.

In order to use commercially available thermostated cell holders, the spectroelectrochemical cell is dimensionally close to the conventional quartz cuvette (outer dimensions $=12.5 \mathrm{~mm} \times 12.5 \mathrm{~mm} \times 45 \mathrm{~mm}$ ). The inner part of the cuvette (Hellma ${ }^{\circledR}$ Analytics) has been specially redesigned in order to insert, parallel to the quartz windows, a home-made interdigitated three $\mathrm{Au}$ electrodes with high precision [13]. Spectrophotometric measurements were carried out in direct reflecting mode on the working electrode with a home-made bench composed of Princeton Instruments modules (light sources, fibers, monochromators, spectroscopy camera and software).

From references [19-21], Beer's law for surface-confined species can be expressed as follows:

Absorbance $=2 \times 1000 . \varepsilon . \Gamma \quad$ with $\left\{\begin{array}{l}\varepsilon, \mathrm{M}^{-1} \mathrm{~cm}^{-1} \\ \Gamma, \mathrm{mol} \mathrm{cm}^{-2}\end{array}\right.$

Note that the 2 factor is due to our spectroelectrochemical setup which imposes an absorption measurement in reflection mode.

\section{Results and discussion}

\subsection{Cyclic voltammetry on mixed SAMs}

As expected [14], SAM of 1 exhibits two successive fully reversible one-electron processes in negative direction, at $-0.60 \mathrm{~V}$ and $-0.75 \mathrm{~V}$ vs. $\mathrm{AgNO}_{3} / \mathrm{Ag}$ (Figure 1). At $298 \mathrm{~K}$, the full steady-state coverage $\left(\Gamma_{\max }\right)$ was estimated to $1.5 \pm 0.110^{-10} \mathrm{~mol} . \mathrm{cm}^{2}$. This value fits with the one assessed in $0.1 \mathrm{M} \mathrm{Bu}_{4} \mathrm{NPF}_{6} / \mathrm{CH}_{3} \mathrm{CN}$ and agrees with previous works [22].The shape of voltammetric waves and the linear dependency between peak intensities and scan rates are characteristic of surface-confined redox species. Estimated by curve fitting from two Generalized Lateral Interactions functions (GLI functions) of equal area on the basis of the procedure from reference [23], the value of full width at half maximum (FWHM) deviates from the expected value (i.e. $\sim 91 \mathrm{mV}$ at $303 \mathrm{~K}$ ) of an "ideal system", based on a Langmuir model (i.e. all adsorption sites are equivalents and there are no interactions between immobilized electroactive centers). 
This effect decreases on mixed SAMs with decreasing surface coverage $(\ulcorner)$, suggesting the presence of interactions between electroactive species only [24-26] (Figure 2). Analysis of the data by curve fitting leads to an estimation of the $S$ and $G$ interaction parameters involved during the first $\left(S_{1} \approx 0\right.$ and $G_{1}=-0.94 \pm 0.03$ ) and second $\left(S_{2} \approx 0\right.$ and $\left.G_{2}=-0.10 \pm 0.03\right)$ reduction steps (Figure $2 A$ ). These values are consistent with strong attractive interaction between 1 and $\mathbf{1}^{-}$and a tiny lateral interaction during the second process. As previously demonstrated on TEMPO based SAMs, a linear dependence of FWHM vs. $\Gamma$ traduces a random distribution and a deviation from linearity at low surface coverage suggests a phase segregation [27]. Because the small gap $(\approx 150 \mathrm{mV})$ between the first and the second apparent redox potential leads to uncertainties in estimating the FWHM at low surface coverage, information about the redox sites distribution cannot be precisely assessed (Figure 2B). Nevertheless, the quasi linearity of FWHM vs. $\Gamma$ seems to indicate that the distribution of redox sites is rather random.

\subsection{Absorption spectroelectrochemistry (A-SEC) on mixed SAMs}

Mixed SAMs of 1 have been studied by A-SEC between 350 and $1700 \mathrm{~nm}$ from $510^{-12}$ to $1.510^{-10} \mathrm{~mol}^{-\mathrm{cm}^{-2}}$ (Figure 3). Note that below $510^{-12} \mathrm{~mol}_{\mathrm{cm}} \mathrm{cm}^{-2}$, raw data are not fully exploitable because of the very low signalto-noise (i.e. the detection limit of our bench is equal to an absorbance value of $10^{-4}$ ).

According to references [14,28], the absorption bands close to 540,640 and $755 \mathrm{~nm}$ are assigned to $\mathbf{1}, \mathbf{1}^{2-}$ and 1" species, respectively. These values were found independent of the surface coverage, suggesting that the molecular structure of electroactive species does not change over the successive dilutions. Surprisingly, absorption maxima values at 540,670 and $755 \mathrm{~nm}$ are not linearly dependent on the surface coverage (Figure 4A). Normalized to the absorption maximum at $\Gamma=\Gamma_{\max }$ for each wavelength, the three curves are superimposable, suggesting that the non-linearity would be independent of the redox processes (Figure 4B). Because the surface coverages assessed by curve fitting of CVs corroborates those estimated by quartz crystal microbalance measurement, the extinction coefficient $(\varepsilon)$ appears to be the only parameter which is likely to vary over the surface coverage (see equation 1 ).

Via the uniaxial refractive index ellipsoid model and by comparing the theoretical approach with experimental data, previous works $[19,20]$ have established that the transmission spectrum of a Langmuir-Blodgett film or organic thin films depends on the tilt angle $(\alpha)$ of the immobilized chromophores, defined with respect to the surface normal direction. In considering these findings and assuming that all PDI species are oriented in the same direction and randomly distributed in the SAM (i.e. a crude approximation), the anisotropic values of extinction coefficient $\varepsilon_{/ /}$and $\varepsilon_{\perp}$ (i.e. parallel and perpendicular projections to the surface normal direction, respectively) of 1 could be expressed [20] as

$$
\left\{\begin{array}{l}
\varepsilon_{\perp}=\frac{3}{2} \varepsilon_{\mathrm{SAM}} \sin ^{2}(\alpha) \\
\varepsilon_{\square}=3 \varepsilon_{\mathrm{SAM}} \cos ^{2}(\alpha)
\end{array} \text { with } \varepsilon_{\mathrm{SAM}}\right. \text { : extinction coefficient in SAM }
$$

Note that the angle $\alpha$ represents the angle between the surface normal and the transition dipole moment and the orientation between this transition dipole and the molecule defines the final molecular orientation. In first approximation, the transition dipole direction might coincide with the long molecular axis of PDI [29-31]. In addition, Figure $4 \mathrm{~b}$ suggests that the orientation of the transition dipole moments for the radical anion at 755 
$\mathrm{nm}$ and for the dianion at $640 \mathrm{~nm}$ are oriented parallel to that of the transition at $540 \mathrm{~nm}$. Even if each should be assigned its own tilt angle, we assume that these three angles are very close.

At this stage, we can also presume that the average tilt angle depends on the surface coverage because the degree of freedom of immobilized redox species increases at low surface coverage [27,2].

Accordingly, the surface coverage dependence of the extinction coefficient could be expressed through $\varepsilon_{\perp}$ (i.e. due to the reflection mode at normal incidence), leading to an $\alpha$-based formula of the Beer's law:

$$
\text { Absorbance }(\Gamma)=2000 \cdot \varepsilon_{\perp}(\Gamma) \cdot \Gamma=3000 \cdot \varepsilon_{\mathrm{SAM}} \cdot \sin ^{2}[\alpha(\Gamma)] . \Gamma
$$

Because $\varepsilon_{\text {SAM }}$ cannot be approximated by the molecular extinction coefficient of species in solution [20], a normalization at $\Gamma=\Gamma_{\max }$ of equation 3 allows to extract an expression of $\alpha$ independent of $\varepsilon_{\text {SAM }}$ :

$$
\alpha(\Gamma)=\arcsin \left[\sin \left[\alpha\left(\Gamma_{\max }\right)\right] \cdot \sqrt{\frac{\text { Absorbance }(\Gamma)}{\text { Absorbance }\left(\Gamma_{\max }\right)} \cdot \frac{\Gamma_{\max }}{\Gamma}}\right]
$$

Note that $\alpha\left(\ulcorner\rightarrow 0)\right.$ depends on the initial value of $\alpha\left(\Gamma_{\max }\right)$.

According to the previous works of Brochsztain et al. [22] and Saavedra et al. [30], the average tilt angle between the PDI molecular axis and the ITO surface normal reaches $30^{\circ}$ at the full surface coverage. On the assumption that $\alpha(\Gamma \max )$ for 1-based SAM on Au substrate is of the same order, the average tilt angle vs $\Gamma$ can be assessed from experimental data (Figure 5). The extrapolation of the tilt angle at the nil surface coverage reaches a value of $70^{\circ}$ leading to a $40^{\circ}$ angle shift at low surface coverage. Such angle changes were previously observed on mixed SAMs [32-34].

\section{Conclusion}

This work shows that absorption spectroelectrochemical experiments on mixed SAMs afford the identification of electroactive species under different redox states or products arising from redox reactions with an absorbance detection limit close to $10^{-4}$.

A-SEC provides an opportunity to probe the structure of the monolayer in order to establish structureproperties relationships. Absorption maxima of a dialkyl disulfide PDI and its reduced forms are not linearly dependent on the surface coverage, probably due to the change of the orientation angle of the electroactive species occurring during the dilution. However, additional data are required to confirm this behavior and understand the impact of the distribution of immobilized chromophores on optical properties.

\section{Acknowledgments}

The authors gratefully acknowledge the MENRT for PhD grants to S. Bkhach. The authors thank Hellma ${ }^{\circledR}$ Analytics and Princeton Instruments companies for the quality of their products and services. This work was supported by the Contrat Plan État Région 2007-2013 (Pays de la Loire - France).

\section{References}

[1] A.L. Eckermann, D.J. Feld, J.A. Shaw, T.J. Meade, Electrochemistry of redox-active self-assembled monolayers, Coord. Chem. Rev. 254 (2010) 1769-1802. doi:10.1016/j.ccr.2009.12.023. 
[2] J.C. Love, L.A. Estroff, J.K. Kriebel, R.G. Nuzzo, G.M. Whitesides, Self-Assembled Monolayers of Thiolates on Metals as a Form of Nanotechnology, Chem Rev. 105 (2005) 1103-1170. doi:10.1021/cr0300789.

[3] S. Zhang, C.M. Cardona, L. Echegoyen, Ion recognition properties of self-assembled monolayers (SAMs), Chem Commun. (2006) 4461-4473.

[4] P.-Y. Blanchard, S. Boisard, M. Dias, T. Breton, C. Gautier, E. Levillain, Electrochemical Transduction on Self-Assembled Monolayers: Are Covalent Links Essential?, Langmuir. 28 (2012) 12067-12070. doi:10.1021/la302142w.

[5] O. Aleveque, T. Breton, E. Levillain, Electrocatalytic activity of nitroxyl mixed self-assembled monolayers: combined effects of the nanoscale organization and the composition, Soft Matter. 8 (2012) 3875-3880.

[6] C. Orain, A.G. Porras-Gutiérrez, F. Evoung Evoung, C. Charles, N. Cosquer, A. Gomila, F. Conan, Y. Le Mest, N. Le Poul, Electrocatalytic reduction of nitrite ions by a copper complex attached as SAMs on gold by "self-induced electroclick": Enhancement of the catalytic rate by surface coverage decrease, Electrochem. Commun. 34 (2013) 204-207. doi:10.1016/j.elecom.2013.06.014.

[7] J. Rivera-Gandía, R.M. Georgiadis, C.R. Cabrera, In-situ fluorescence spectroscopy of self-assembled monolayers of HS- $(\mathrm{CH} 2)$ n-fluorescein and HS- $(\mathrm{CH} 2) 6$-poly(dT)18-fluorescein at gold electrodes under cyclic voltammetric conditions, J. Electroanal. Chem. 621 (2008) 75-82. doi:10.1016/j.jelechem.2008.04.028.

[8] J.L. Shepherd, A. Kell, E. Chung, C.W. Sinclar, M.S. Workentin, D. Bizzotto, Selective Reductive Desorption of a SAM-Coated Gold Electrode Revealed Using Fluorescence Microscopy, J. Am. Chem. Soc. 126 (2004) 8329-8335. doi:10.1021/ja0494095.

[9] M. Tagliazucchi, L.P.M. De Leo, A. Cadranel, L.M. Baraldo, E. Völker, C. Bonazzola, E.J. Calvo, V. Zamlynny, PM IRRAS spectroelectrochemistry of layer-by-layer self-assembled polyelectrolyte multilayers, J. Electroanal. Chem. 649 (2010) 110-118. doi:10.1016/j.jelechem.2010.02.013.

[10] W.F. Paxton, S.L. Kleinman, A.N. Basuray, J.F. Stoddart, R.P. Van Duyne, Surface-Enhanced Raman Spectroelectrochemistry of TTF-Modified Self-Assembled Monolayers, J. Phys. Chem. Lett. 2 (2011) 1145-1149. doi:10.1021/jz200523q.

[11] I. Ashur, O. Schulz, C.L. McIntosh, I. Pinkas, R. Ros, A.K. Jones, Transparent Gold as a Platform for Adsorbed Protein Spectroelectrochemistry: Investigation of Cytochrome c and Azurin, Langmuir. 28 (2012) 5861-5871. doi:10.1021/la300404r.

[12] O. Ivashenko, J.T. van Herpt, B.L. Feringa, P. Rudolf, W.R. Browne, Electrochemical Write and Read Functionality through Oxidative Dimerization of Spiropyran Self-Assembled Monolayers on Gold, J. Phys. Chem. C. 117 (2013) 18567-18577. doi:10.1021/jp406458a.

[13] O. Alévêque, E. Levillain, L. Sanguinet, Spectroelectrochemistry on electroactive self-assembled monolayers: Cyclic voltammetry coupled to spectrophotometry, Electrochem. Commun. 51 (2015) 108112. doi:10.1016/j.elecom.2014.12.014.

[14] S. Bkhach, Y. Le Duc, O. Alévêque, C. Gautier, P. Hudhomme, E. Levillain, Highly Stable Perylenediimide-Based Self-Assembled Monolayers Studied with Spectroelectrochemistry, ChemElectroChem. 3 (2016) 887-891. doi:10.1002/celc.201600034.

[15] Z. Chen, M.G. Debije, T. Debaerdemaeker, P. Osswald, F. Würthner, Tetrachloro-substituted Perylene Bisimide Dyes as Promising n-Type Organic Semiconductors: Studies on Structural, Electrochemical and Charge Transport Properties, ChemPhysChem. 5 (2004) 137-140. doi:10.1002/cphc.200300882.

[16] S. Leroy-Lhez, J. Baffreau, L. Perrin, E. Levillain, M. Allain, M.-J. Blesa, P. Hudhomme, Tetrathiafulvalene in a Perylene-3,4:9,10-bis(dicarboximide)-Based Dyad: A New Reversible Fluorescence-Redox Dependent Molecular System, J. Org. Chem. 70 (2005) 6313-6320. doi:10.1021/jo050766n.

[17] F. Würthner, Bay-substituted perylene bisimides: Twisted fluorophores for supramolecular chemistry, Pure Appl. Chem. 78 (2006) 2341-2349. doi:10.1351/pac200678122341.

[18] O. Alévêque, P.-Y. Blanchard, T. Breton, M. Dias, C. Gautier, E. Levillain, Revisiting the determination of full steady-state coverage of redox centers on self-assembled monolayers, Electrochem. Commun. 16 (2012) 6-9. doi:10.1016/j.elecom.2011.12.014.

[19] T. Hasegawa, S. Takeda, A. Kawaguchi, J. Umemura, Quantitative Analysis of Uniaxial Molecular Orientation in Langmuir-Blodgett Films by Infrared Reflection Spectroscopy, Langmuir. 11 (1995) 12361243. doi:10.1021/la00004a032.

[20] T. Hasegawa, Y. Ushiroda, M. Kawaguchi, Y. Kitazawa, M. Nishiyama, A. Hiraoka, J. Nishijo, UV absorption spectroscopic analysis of the molecular orientation of a drug penetrated into a DPPC membrane, Langmuir. 12 (1996) 1566-1571.

[21] T. Tang, J. Qu, K. Müllen, S.E. Webber, Molecular Layer-by-Layer Self-Assembly of Water-Soluble Perylene Diimides through $\pi-\pi$ and Electrostatic Interactions, Langmuir. 22 (2006) 26-28. doi:10.1021/la052766o. 
[22] B.P.G. Silva, D.Z. de Florio, S. Brochsztain, Characterization of a Perylenediimide Self-Assembled Monolayer on Indium Tin Oxide Electrodes Using Electrochemical Impedance Spectroscopy, J. Phys. Chem. C. 118 (2014) 4103-4112. doi:10.1021/jp409416b.

[23] O. Alévêque, E. Levillain, A generalized lateral interactions function to fit voltammetric peaks of selfassembled monolayers, Electrochem. Commun. 67 (2016) 73-79. doi:10.1016/j.elecom.2016.04.003.

[24] E. Laviron, General expression of the linear potential sweep voltammogram in the case of diffusionless electrochemical systems, J. Electroanal. Chem. 101 (1979) 19-28.

[25] O. Aleveque, P.Y. Blanchard, T. Breton, M. Dias, C. Gautier, E. Levillain, F. Seladji, Nitroxyl radical selfassembled monolayers on gold: Experimental data vs. Laviron's interaction model, Electrochem. Commun. 11 (2009) 1776-1780. doi:10.1016/j.elecom.2009.07.015.

[26] O. Aleveque, P.Y. Blanchard, C. Gautier, M. Dias, T. Breton, E. Levillain, Electroactive self-assembled monolayers: Laviron's interaction model extended to non-random distribution of redox centers, Electrochem Commun. 12 (2010) 1462-1466. doi:10.1016/j.elecom.2010.07.039.

[27] O. Aleveque, C. Gautier, M. Dias, T. Breton, E. Levillain, Phase segregation on electroactive selfassembled monolayers: a numerical approach for describing lateral interactions between redox centers, Phys Chem Chem Phys. 12 (2010) 12584-12590. doi:10.1039/c0cp00085j.

[28] R.O. Marcon, S. Brochsztain, Highly Stable 3,4,9,10-Perylenediimide Radical Anions Immobilized in Robust Zirconium Phosphonate Self-Assembled Films, Langmuir. 23 (2007) 11972-11976. doi:10.1021/la702642h.

[29] P.A.J. De Witte, J. Hernando, E.E. Neuteboom, E.M.H.P. van Dijk, S.C.J. Meskers, R.A.J. Janssen, N.F. van Hulst, R.J.M. Nolte, M.F. García-Parajó, A.E. Rowan, Synthesis and Characterization of Long Perylenediimide Polymer Fibers: From Bulk to the Single-Molecule Level, J. Phys. Chem. B. 110 (2006) 7803-7812. doi:10.1021/jp057009d.

[30] Y. Zheng, A.J. Giordano, R.C. Shallcross, S.R. Fleming, S. Barlow, N.R. Armstrong, S.R. Marder, S.S. Saavedra, Surface Modification of Indium-Tin Oxide with Functionalized Perylene Diimides: Characterization of Orientation, Electron-Transfer Kinetics and Electronic Structure, J. Phys. Chem. C. 120 (2016) 20040-20048. doi:10.1021/acs.jpcc.6b06812.

[31] H.J. Park, M.C. So, D. Gosztola, G.P. Wiederrecht, J.D. Emery, A.B.F. Martinson, S. Er, C.E. Wilmer, N.A. Vermeulen, A. Aspuru-Guzik, J.F. Stoddart, O.K. Farha, J.T. Hupp, Layer-by-Layer Assembled Films of Perylene Diimide- and Squaraine-Containing Metal-Organic Framework-like Materials: Solar Energy Capture and Directional Energy Transfer, ACS Appl. Mater. Interfaces. 8 (2016) 24983-24988. doi:10.1021/acsami.6b03307.

[32] F. Schreiber, Structure and growth of self-assembling monolayers, Prog. Surf. Sci. 65 (2000) 151-257. doi:10.1016/S0079-6816(00)00024-1.

[33] M. Zwahlen, S. Tosatti, M. Textor, G. Hähner, Orientation in Methyl- and Hydroxyl-Terminated SelfAssembled Alkanephosphate Monolayers on Titanium Oxide Surfaces Investigated with Soft X-ray Absorption, Langmuir. 18 (2002) 3957-3962. doi:10.1021/la015692z.

[34] P. Gupta, A. Ulman, S. Fanfan, A. Korniakov, K. Loos, Mixed Self-Assembled Monolayers of Alkanethiolates on Ultrasmooth Gold Do Not Exhibit Contact-Angle Hysteresis, J. Am. Chem. Soc. 127 (2005) 4-5. doi:10.1021/ja044623e. 

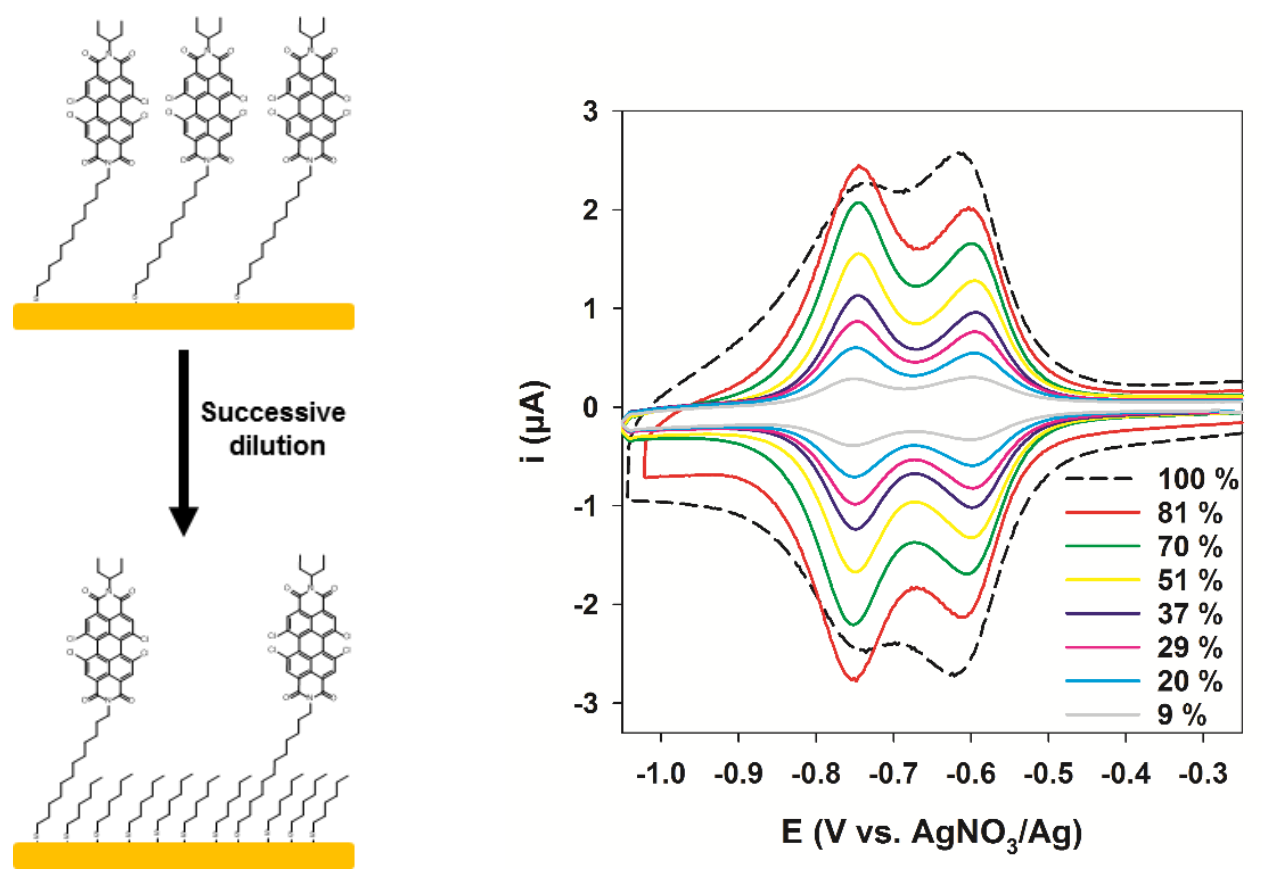

Figure 1. Cyclic voltammetry of mixed SAMs in $0.1 \mathrm{M} \mathrm{Bu}_{4} \mathrm{NPF}_{6} / \mathrm{CH}_{2} \mathrm{Cl}_{2}$ at $100 \mathrm{mV} . \mathrm{s}^{-1}$ and $303 \mathrm{~K}$ in glovebox. The surface coverages are expressed as percentage of the full steady-state coverage. It is noteworthy that the reproducible shape of the CV at $100 \%$ (dash line) is different from the ones of mixed SAMs and was previously published in reference 14 . Also note that same electrochemical behavior was observed with mixed SAMs prepared from successive dilutions with octa, dodeca and octadeca-nethiols. 

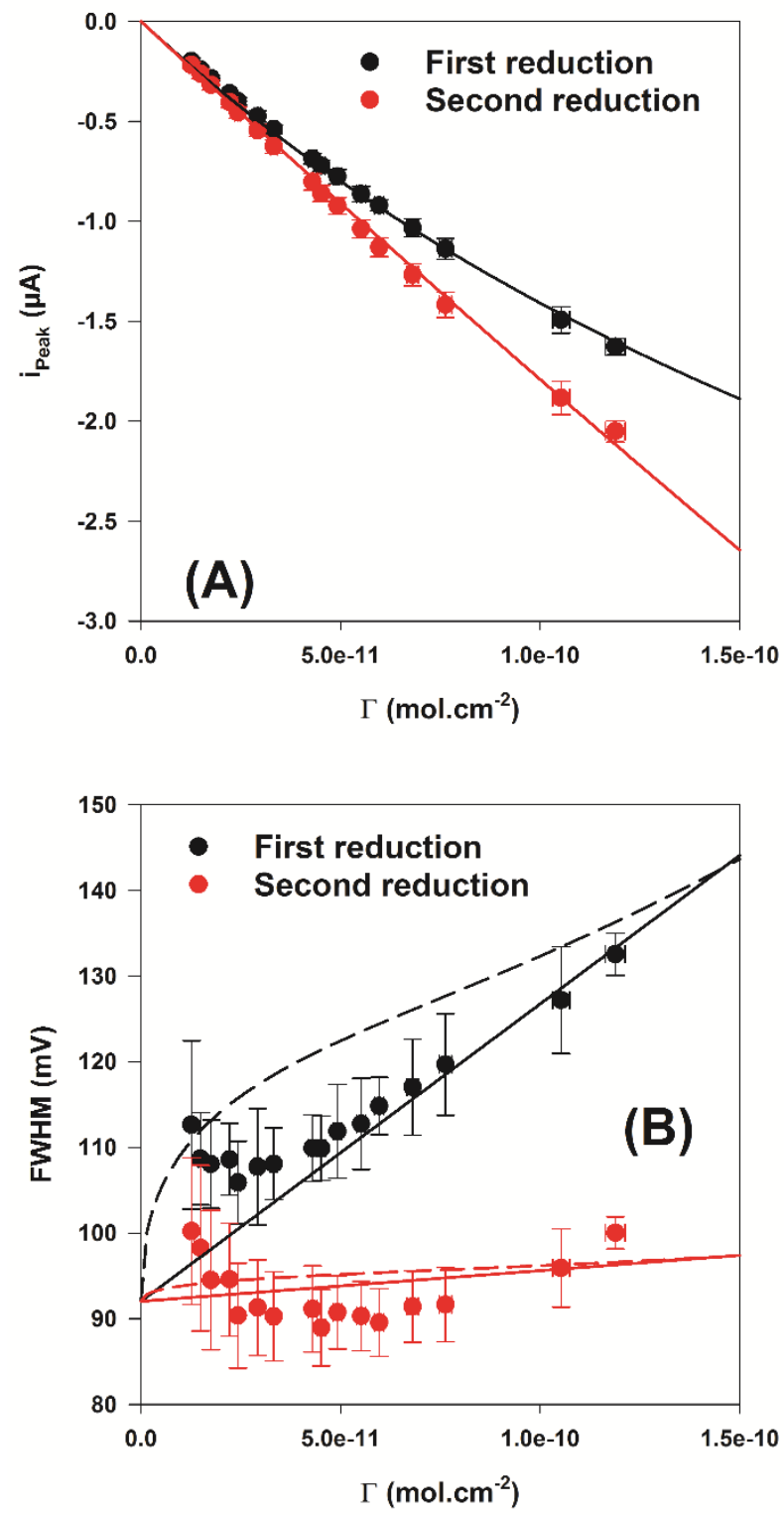

Figure 2. Fitted parameter extracted from CVs of mixed SAMs in $0.1 \mathrm{M} \mathrm{Bu}_{4} \mathrm{NPF}_{6} / \mathrm{CH}_{2} \mathrm{Cl}_{2}$ at $100 \mathrm{mV} \cdot \mathrm{s}^{-1}$ and $303 \mathrm{~K}$.

(A) Peak intensity vs. surface coverage. The solid lines correspond to a random distribution (Laviron's model $-\mathrm{i}_{\text {Peak }}(\Gamma)=\frac{\mathrm{n}^{2} \mathrm{~F}^{2} v \mathrm{~A}}{\mathrm{RT}} \frac{\Gamma}{2\left(2-\mathrm{G} \frac{\Gamma}{\Gamma_{\max }}\right)}$ with $\mathrm{A}=$ area and $\mathrm{v}=$ scan rate $)$ with $\mathrm{G}_{1}=-0.94 \pm 0.03$ and $\mathrm{G}_{2}=-0.10 \pm$ 0.03 , extracted by fitting of experimental data.

(B) FWHM vs. surface coverage. The solid lines correspond to a random distribution (Laviron's model) and the dash lines to a phase segregation model, which have been simulated with the previous values of $G_{1}$ and $\mathrm{G}_{2}$. 

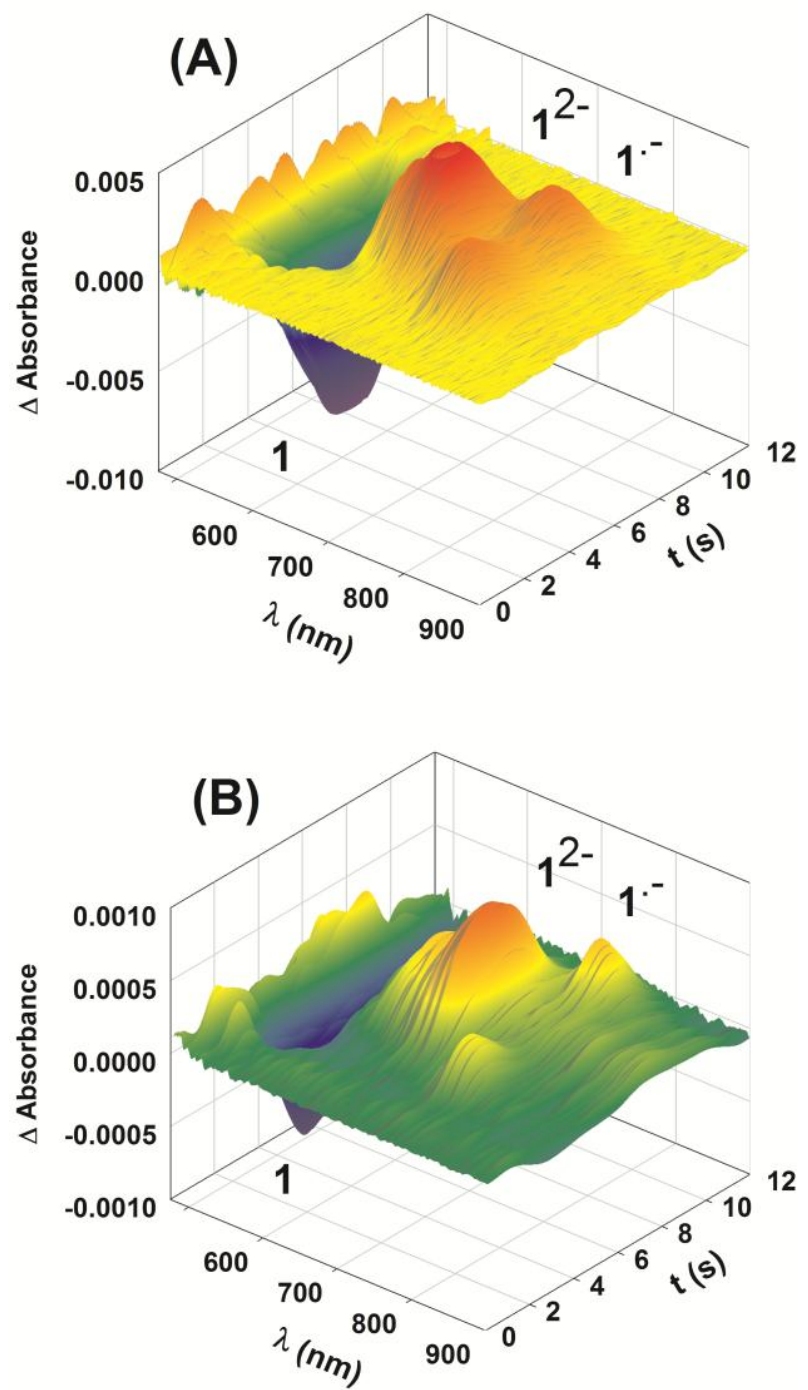

Figure 3: Absorption spectroelectrochemical experiments on mixed SAMs in $0.1 \mathrm{M} \mathrm{Bu}_{4} \mathrm{NPF}_{6} / \mathrm{CH}_{2} \mathrm{Cl}_{2}$ at $10 \mathrm{mV} . \mathrm{s}^{-1}$ and $293 \mathrm{~K}$. Note that the absorbance at a given potential was determined by comparison with a reference spectrum recorded at the equilibrium potential [14].

(A) $\Gamma=1.45 \pm 0.0610^{-10} \mathrm{~mol} . \mathrm{cm}^{2}$, i.e. $96 \%$ of the full steady-state coverage.

(B) $\Gamma=5.6 \pm 0.210^{-12} \mathrm{~mol} . \mathrm{cm}^{2}$, i.e. $4 \%$ of the full steady-state coverage. 

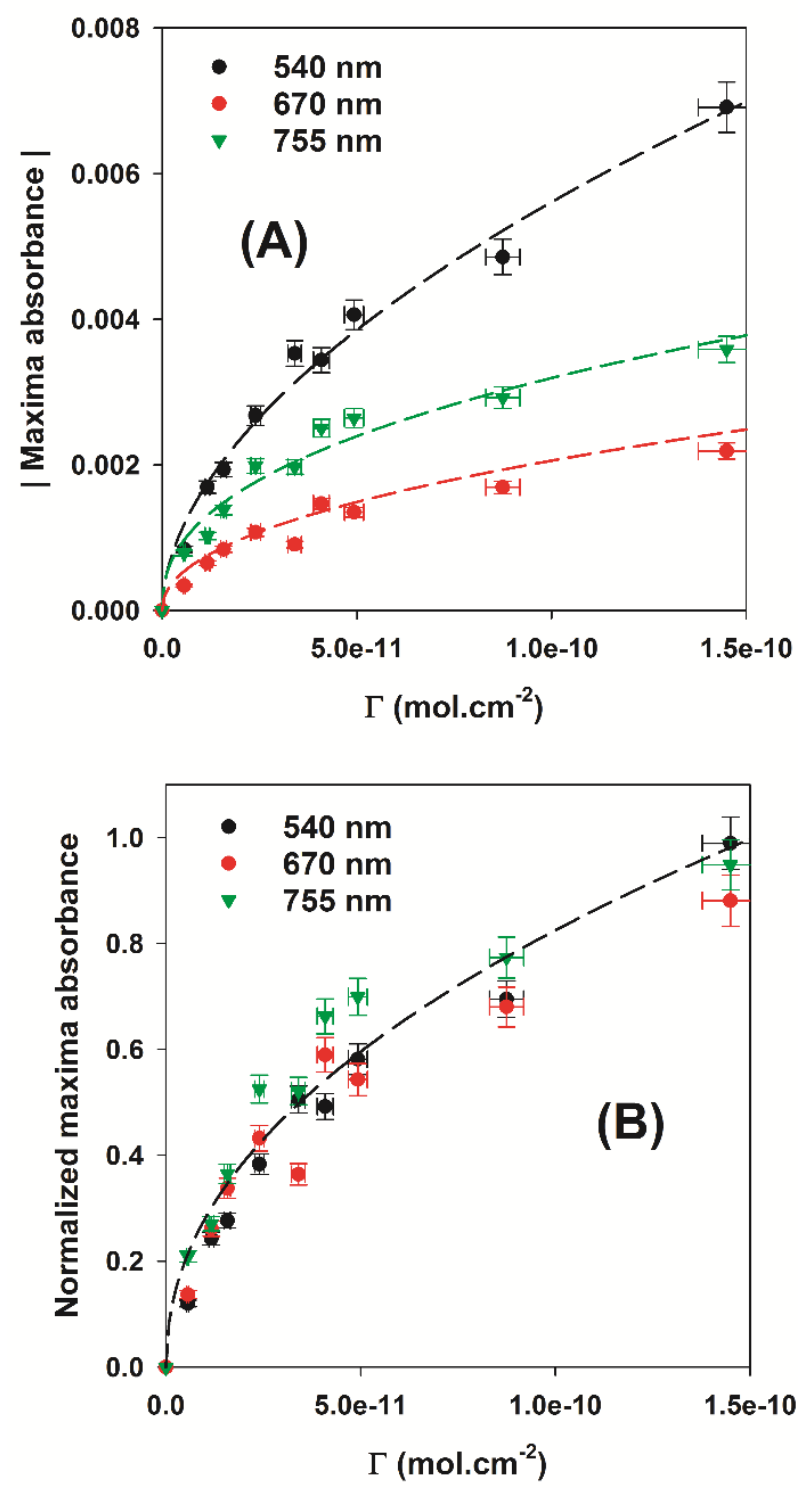

Figure 4. Data processing from A-SEC.

(A) Absorption maxima at 540, 670 and $755 \mathrm{~nm}$ extracted from adsorption spectroelectrochemical experiments of mixed SAMs in $0.1 \mathrm{M} \mathrm{Bu}_{4} \mathrm{NPF}_{6} / \mathrm{CH}_{2} \mathrm{Cl}_{2}$ at $10 \mathrm{mV} \cdot \mathrm{s}^{-1}$ and $303 \mathrm{~K}$. The dash lines are trend curves.

(B) Normalized absorbance maxima (right y-axis) vs. surface coverage. The absorbance values were normalized to $100 \%$ at $\Gamma=\Gamma_{\max }$. The dash line is a trend curve. 


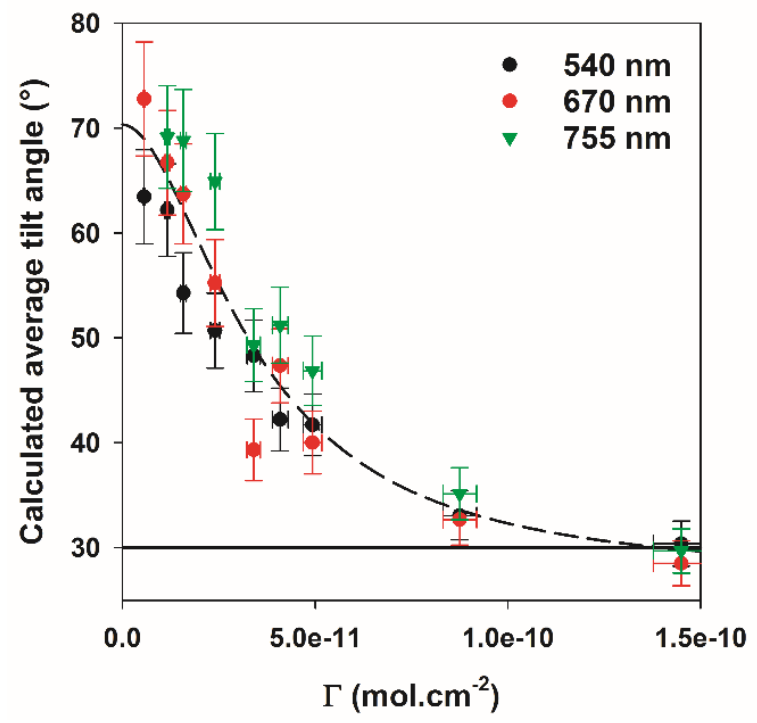

Figure 5. Calculated average tilt angle (left y-axis) vs. surface coverage. The solid line visualizes the arbitrary value of tilt angle at the full steady-state coverage (i.e. $30^{\circ}$ ). The dash line is a trend curve. 